\title{
Ellipsis or Compression? (With Special Reference to English Modal Adverbs)
}

\author{
Yelena Mkhitaryan ${ }^{1, *}$, Zara Kostanian ${ }^{2}$ \\ ${ }^{1}$ Faculty of Foreign Languages, Kh. Abovyan Armenian State Pedagogical University, Armenia \\ ${ }^{2}$ Faculty of Foreign Languages and Regional Studies, Lomonosov Moscow State University, Russian Federation
}

Copyright $\subset 2017$ by authors, all rights reserved. Authors agree that this article remains permanently open access under the terms of the Creative Commons Attribution License 4.0 International License

\begin{abstract}
The paper examines the underlying origin of English modal adverbs known in linguistics also as disjuncts. It is acknowledged that disjuncts are semantic derivations of identical adverbs functioning as adverbial modifiers of manner. We assume that disjuncts (certainly, frankly, etc.) have passed through a number of reconstructive operations before they come to be used as such, i.e. parentheses expressing the speaker's attitude to the whole utterance. The basic aim of the research is to find out what constructions underlie these lexical units and what kind of reconstructions the latter undergo before they come to be used as disjuncts. The research is carried out in the framework of cognitive and transformational grammar. The results of the study allow us to state that lexical units of this type are the outcome of various kinds of reconstructions, which, in addition to ellipsis, include deletion, substitution, movement, expansion, etc. Each of these reconstructions generally recognized as compression defines a transformational step which the underlying structures take before obtaining their final form as single units. The paper also examines cases with some adjectives occurring in the initial position, which makes them identical to the respective adverbs functioning as disjuncts.
\end{abstract}

Keywords Language Economy, Attitudinal Disjuncts, Style Disjuncts, Ellipsis, Compression, Substitution, Deletion, Movement, Expansion

\section{Introduction}

\subsection{Principle of Language Economy}

The problem of structural changes in language towards shortening always attracted the attention of linguists at different periods. It is still relevant nowadays in view of ever-increasing tendency of language towards economy. This can in the first place be accounted for by the increasing tempo and rhythm of human life, enormous amount of information of various kinds people get every day as well as their active participation in various spheres of life, which requires short, brief and laconic forms of expression. Many researchers point out the rapid shortening of sentences in Modern English leading to the reduction of composite sentences to simple ones, simple sentences in their turn to word-combinations, or single words, etc. [1, 2, 3]. As B. Foster notes, in Modern English, especially in recent years, the process of compression of nominal phrases has reached its peak. The linguist regards the abundant usage of compressed word-combinations as a kind of 'epidemic' [1, 190]. The reduction of syntactic structures occurs at the expense of deleting the rudimentary elements of the structure and preservation of its logical-semantic nucleus, thanks to which speakers or hearers can easily comprehend the full meaning of the sentence. A. Martinet, who made a great contribution in the study of language economy, notes that language revolution is usually characterized by the contradiction between the human need for communication and their desire to minimize their mental and physical activity. Language behavior, the linguist emphasizes, is regulated by the principle of least efforts [4].

\subsection{Ellipsis vs. Compression}

Language economy is realized through the process of reduction, which implies not only the mechanical deletion of the rudimentary parts of the structure, i.e. ellipsis, but also their replacement, by less complicated and lengthy elements. If in the first case the situation is more or less clear, the same cannot be said about reconstructions of the second type. There has been much dispute concerning the status of this form of structural reduction, with many linguists viewing it as compression, and others relating it to ellipsis. But one point that almost all linguists agree on is that compression is wider in meaning and more complex in realization than ellipsis. As I. Vardul notes, compression is characterized not only by deletion of some elements of the structure, but also by deformation of non-ellipted part of the structure $[5,303]$. The same view is held by A. Larkina, according to whom 
compression is a more complex, wider and abstract multilevel phenomenon, while ellipsis is a concrete actualization of compression [6, 2]. B. Dyundik in his "Compression and Some Problems of Translation" writes that compression provides the simplification of the structure, meanwhile conveying the same scope of information mechanical deletion of some elements of the structure $[7 ; 8$, $156 ; 9,169 ; 10 ; 11,180-181]$. According to A. Radford, Ellipsis is an operation by which an expression is omitted in the sense that its phonetic features are deleted and so unpronounced [10, 455]. Matthews' definition sounds as follows: "Ellipsis is the omission of one or more elements from a construction, especially when they are supplied by the context" [12].

Elliptical structures are compressive by nature, but the basic condition of their existence is the presence of their complete form $[6,2]$. As we see ellipsis is viewed as being narrower in meaning and function than compression, standing in the same hyponymic relation to the latter as deletion, substitution, abbreviation, etc.

Some linguists use the term 'condensation' instead of 'compression', but we do not see any conceptual difference between these terms. Thus, according to D. Biber et al., condensation involves a structural rearrangement, frequently including the addition of extra words. The linguists view ellipsis as "the principal type of condensation" $[8,115]$. We will add here that the term 'condensation' was suggested by one of the founders of the Prague Functional School V. Mathesius, who, however, used the term in reference only to the replacement of a subordinate clause by a nominal phrase [12].We view compression in a wider sense, including into it a word-combination, a sentence, a supra-phrasal unity and even a text.

\section{Transformational - Cognitive Origin of Disjuncts}

\subsection{Disjuncts Examined in the Light of Grammatical Semantics}

Our basic task is to find out how the linguistic units of the probably, frankly type come to function independently, changing their status of adjunct to that of disjunct. These lexemes constitute the most compressed form of expression of the speaker's attitude towards the utterance. They are termed differently by linguists: sentence modifying adverbs [13], disjuncts [14]; sentence adverbials [15], clause level modifiers [11], etc. We use the term suggested by R. Quirk and S. Greenbaum [14, 242], who define them as disjuncts showing the speaker's attitude towards what is being said with respect to the content of communication (attitudinal disjuncts) or form of communication (style disjuncts).

According to some linguists the lexical units under study are shortened forms of a full sentence. For example, Certainly they will come is equivalent to It is certain that they will come. This approach is maintained by R. Quirk and
S. Greenbaum and other linguists. They hold that the disjuncts probably, certainly, possibly, fortunately, etc. are paraphrases or correspondences of constructions with the introductory it, preceding the base clause [14, 243-244; 16; 17]. G. Payne, who holds almost the same view, notes that the meanings of the clause level modifiers (this is his term for disjuncts) can usually be paraphrased with another structure. For example, Luckily, the restaurant was open corresponds to I consider it lucky that the restaurant was open $[11,249]$. Shuan-Fan Huang (like some other linguists) defines the relations between these adverbs and their corresponding forms as synonymous structures [18, 49-53], which is practically identical to the view expressed above. So the general assumption is that most modal adverbs can have parallel constructions: Probably =It is probable; Evidently = It is evident; Surprisingly $=$ It is surprising; Fortunately $=$ It is fortunate; Clearly=It is clear, etc.

This kind of interpretation of the correlation between disjuncts and their synonymous expressions comes to prove that these utterances are seen to include two propositions. So the utterance It is certain that he will come consists of two clauses: a) It is certain, b) They will come.

\subsection{Disjuncts Examined in the Light of Cognitive Linguistics}

Viewed in the framework of cognitive linguistics such constructions like Certainly, they will come are given a different interpretation. Though the above sentence is composite in structure, conceptually it represents one simple utterance as it expresses one propositional situation: the speaker's attitude to what is being said. As K. Hyland points out, this kind of devices (hedges) do not fit into a neat scheme of discrete categories which allow one meaning to be clearly distinguished from others. [19,437]. Shuan-Fan Huang illustrates the example Surprisingly, John came this morning, noting that the role of surprisingly is to express an external evaluation of the event in general and "the sentence as a whole describes the fact that John's coming this morning was surprising $[18,26]$. I. Kobrina et al. claim that the scope of information is concentrated in the subordinate clause, the main clause being the bearer of epistemic meaning. As a result, the main clause is devoid of the communicative completeness and independence, therefore is easily subjected to reduction $[20,196-197 ; 349]$. So according to cognitive linguists, the utterance Certainly they are aware of the accident is presented as information that can be taken as a fact. The same utterance containing another disjunct, for example, Unfortunately, they are aware of the accident conveys quite a different modality to the utterance: regret. So disjuncts can be regarded as a powerful tool of manipulating the listener's or reader's perception of the information, thus making them accept the proposed vector of evaluating and interpreting the described facts and events. The clause It is certain and the attitudinal disjunct Certainly are propositional variants or as R. Quirk and S. Greenbaum claim, they present a close correspondence to one another, 
expressing the same epistemic meaning [14, 94].

Modal adverbs can also be described from the point of view of force dynamics, a notional category proposed by L. Talmy, a well-known cognitivist linguist. L. Talmy applies this concept to structure and organize meaning. This concept implies the exertion of force, resistance to such force, the overcoming of such force, blockage of a force, the removal of such blockage, and so forth. The linguist effectively used this semantic category in examining modal verbs, in both their basic and epistemic usages. We assume that this category can be transferred to the study of modal adverbs in their epistemic usage as well. L. Talmy wrote, "Force dynamics can be seen to operate in discourse, preeminently in directing patterns of argumentation, but also in guiding discourse expectations and their reversal" [21, 49-50]. So we can say that modal adverbs or disjuncts may also be described within a framework of argumentation and interpretation, particularly in expressing the speaker's attitude towards the utterance, characterizing the latter from the point of certainty, probability, possibility, (un)desirability, truth, clarity, etc. But this implies a special, more extensive study, which is beyond the scope of the present paper.

\subsection{Disjuncts as Examined in Transformational Grammar}

Our task is to trace transformational processes that lead to the change of clauses like It is certain to the corresponding modal adverbs. In other words, we aim to find out what types of reconstructions underlie these processes: ellipsis or other form of compression. We will try to describe this phenomenon by employing the theory of transformational grammar.

Though most cognitive linguists tend to distance themselves from transformationalists, rejecting such concepts as deep/ surface structure, transforms, transformational rules, etc., some of cognitivist linguists acknowledge its usefulness in analyzing certain linguistic facts [22]. Following this approach we will examine the underlying history of luckily and honestly in the framework of transformational theory. We suppose that these lexemes and their synonymous structures can be viewed as surface manifestations of the deep structures: The speaker+ attitude+ $\mathrm{P}$ (proposition) $\rightarrow$ for attitudinal disjuncts and the speaker + form of expression $+\mathrm{P} \rightarrow$ for style disjuncts. These deep structures correspond to the following parallel surface structures - I consider it lucky that (or It is lucky that) and I say in a clear way. Determined by the language tendency toward economy, these constructions are subject to various types of compression, including ellipsis.

2.3.1. Now we will show what kind of transformational rules are applied in the process of changing these clauses into modal adverbs (or modal phrases). Consider the following example:

It is certain that they will come. $\rightarrow$ Certainly, they will come.
Here we observe a three-step transformation which includes:

(1) Deletion (It is... that $\rightarrow 0$ )

(2) Substitution (Adj $\rightarrow$ Adv: certain $\rightarrow$ certainly)

(3) Movement (Adv $\rightarrow$ front position)

The substitution of the adjective for the corresponding adverb is required by the new status of the lexical unit: unlike the adjective the modal adverb placed in the front position approaches the function of an adverbial modifier of manner, but with a different function and modification of semantic meaning.

\subsubsection{Constructions with a Style Disjunct May Require a Four-Step Transformation. Consider the following example}

I speak to you in an honest way that I do not trust him. $\rightarrow$ Speaking honestly,

I do not trust him.

This utterance requires the application of four transformational rules.

(1) Substitution $^{1}$ (clause $\rightarrow$ phrase: I speak $\rightarrow$ Speaking)

(2) Deletion(to you $\rightarrow \mathrm{O}$ )

(3) Substitution ${ }^{2}$ (the adjectival phrase $\rightarrow$ adverb: in an honest way $\rightarrow$ honestly)

(4) Deletion (that $\rightarrow$ O)

The modal phrase may undergo further reduction through ellipsis:

Speaking honestly $\rightarrow$ Honestly

\subsubsection{The Following Epistemic Utterance Requires A Five-Step Transformation.}

I consider it prudent (wise, right) of him to accept the offer $\rightarrow$

Prudently (wisely, rightly), he accepted the offer.

(1) Deletion (I consider it $\rightarrow O$ )

(2) Substitution ${ }^{1}$ (of him $\rightarrow$ he)

(3) Substitution ${ }^{2}$ (the infinitive $\rightarrow$ the clause: to accept $\rightarrow$ He accepted)

(4) Substitution ${ }^{3}$ (Adj $\rightarrow$ Adv: prudent (wise, right) $\rightarrow$ prudently (wisely, rightly)

(5) Movement (Adv $\rightarrow$ the front position)

As we see, in addition to the deletion of the first part of the construction [1], there are a number of substitutions [2,3,4], the move operation [5] carrying the adverb to the frontal position and as a result we have a single word. It is obvious that this kind of rearrangement leads to the increasing semantic role of the adverb in the structure of the sentence, imparting a strong epistemic mode to the whole utterance.

2.3.4. In Case of Transformational Ambiguity the Addition of a New Element is Required, Namely For-Phrase, Which is Added to the Disjunct to Remove the Ambiguity. 
Here belong the disjucts fortunately, surprisingly, wisely, rightly, etc. For example, the utterance Fortunately, Henry was very soon offered a new job sounds ambiguous, for it is not clear for whom the fact of Henry's being very soon offered a new job appears to be fortunate. It corresponds to at least three underlying structures:

(1) Henry considers it fortunate that he was very soon offered a new job.

(2) His wife (mother, sister, etc.) considers it fortunate that Henry was very soon offered a new job.

(3) Henry's former boss finds it fortunate that Henry was very soon offered a new job.

The transformational ambiguity may be removed by expanding the disjunct with for-phrase.

(1) Fortunately for Henry, he was very soon offered a new job.

(2) Fortunately for his wife (mother, sister), Henry was very soon offered a new job.

(3) Fortunately for his former boss, Henry was very soon offered a new job.

All these changes including ellipsis, substitution and expansion lead to the multifunctional reconstruction of the structure, which we recognize as compression.

\section{Adjectives Functioning as Disjuncts}

Of special interest are constructions with some adjectives (true, strange, lucky) in the initial position, which brings them close to the functional status of modal adverbs. Consider the following adjective true in the sentences in which it functions as disjunct.

- True, things aren't quite how they are described.

The adjective true in the sentence can easily be replaced by the corresponding adverb in its epistemic meaning:

- Truly, things aren't quite how they are described.

Quirk and Greenbaum, who examined the frontal position of the adjective strange in the structure of the sentence, hold that the implied subject of the adjective can be the whole of the subordinate clause. They claim that the sentence Strange, it was she who initiated divorce proceedings is equivalent to That it was she who initiated divorce proceedings is strange. But then the linguists compare this sentence with Strangely, it was she who initiated divorce proceedings, claiming that there is "little or no difference in meaning" between them [14,119-120].

We agree that there is almost full semantic equivalence between these two constructions; however, the difference concerns the derivational nature of the lexemes strange and strangely. Strange is the result of ellipsis:

It is strange that it was she who initiated divorce proceedings $\rightarrow$ Strange, it was she who initiated divorce proceedings.

Strangely is the output of compression obtained by a number of transformations just like it is observed in case with certainly. The same interpretation can be assigned to the pair true -truly.

Other adjectives are occasionally found functioning the same way. Here is an example with lucky taken from the Internet [23].

- Lucky Jay is quite tall, so he just got in and carried them (the drowning boys) out.

The occurrence of an adjective in the initial position is not always the indicator of its functioning as disjunct. Consider the sentence

- Furious, he could not utter a word.

The adjective furious cannot be viewed as disjunct as it is part of the complete adverbial clause: As he was furious, he could not utter a word. Besides, sentences of this type cannot have a parallel construction, which is the basic prerequisite of existence of an ellipsis. We cannot say *As he was furiously, he could not utter a word. The occurrence of furious at the beginning of the sentence is the result of systemic ellipsis, which allows this kind of reduction in case of an adverbial clause. Cf:

- As he was tired, he could not continue his work. $\rightarrow$ Tired, he could not continue his work.

- Even though they were fresh and delicate in the air, the roses turned stale inside the room. $\rightarrow$ Fresh and delicate in the air, the roses turned stale inside the room.

- As Charlie was anxious, he shook hands with them quickly and presented them to Lincoln and Marion.

- Anxious, Charlie shook hands with them quickly and presented them to Lincoln and Marion. (fict)

If we analyze the cases with the above adjectives from the semantic perspective we will see that they represent quite a different lexical group which shows the physical or emotional state of the subject: anxious, tired, furious, fresh and delicate. In contrast to them the adjectives functioning as disjuncts (strange, true, and lucky) point out the speaker's attitude towards the utterance. Consider the examples with adjectives of the first type:

- Very white, he turned to the balcony and gazed on the square. (fict)

- And at four, dissatisfied with her indifference, her lack of feeling for important things, he moved downstairs and began attending to it himself. (fict)

- She stood in the middle of the room, pale and speechless. (fict)

As is seen from the above examples, the adjectives and adjectival phrases appear in the initial, medial and final position, a feature that is also characteristic of attitudinal disjuncts.

Of special interest is the following example:

- He seemed to have a strange desire, quite unreasonable, for revenge upon women.(fict) 
It might seem quite logical to suppose that the antecedent of the loose attribute quite unreasonable is the noun desire:

- He seemed to have a strange, quite unreasonable desire for revenge upon women.

On the other hand, we might assume that the underlying function of the above phrase is that of disjunct because it expresses the speaker's (or the author's) evaluative attitude to the noun desire, positioned after its antecedent and is set off with commas on both sides. The peculiarity of this case is that the antecedent of the disjunct is not the whole utterance, which is the typical condition for functioning of the disjunct, but an individual element of the structure, i.e. desire. If we suppose that quite reasonable could refer to the whole utterance, the structure of the sentence could take a different shape, with the substitution of the adjective for the relevant adverb: unreasonable $\rightarrow$ unreasonably:

- Quite unreasonably, he seemed to have a strange desire for revenge upon women.

However, we are more inclined to think that the phrase quite unreasonable is a loose attribute relating to the noun desire and functioning as disjunct for it. This is somehow incompatible with the stereotyped concept of disjuncts which are normally seen as referring to the whole utterance.

So we see that some adjectives occurring in the front position can function as modal adverbs or disjuncts. They should be distinguished from those adjectives whose primary function in the sentence is loose attribute. The application of the transformational method helps determine whether the adjective in the initial position appears in epistemic meaning or functions as a loose attribute having implicit adverbial meaning. In some cases a loose attribute can be found functioning in the capacity of disjunct referring to an individual element of the structure.

\section{Conclusions}

The tendency of language towards economy is expressed through linguistic compression, which occurs on almost all language levels and manifests itself in various forms and scope. Compression is opposed to ellipsis which implies only the mechanical deletion of rudimentary parts of the structure and the basic condition of which is the presence of its complete variant in language. Compression is a complex, multi-functional category including, in addition to ellipsis, such transformational operations as deletion, substitution, expansion, movement, etc. Modal adverbs or disjuncts (attitudinal and style) can be viewed as the result not of ellipsis only but other types of compression as well. Some adjectives appearing in the initial position of the construction may function as disjuncts, thus adding to the list of epistemically-bound lexical units. However, not all adjectives appearing in the initial position can function as disjuncts. The transformational method helps clarify their syntactic function in the sentence. The reduction of structures with an adjective functioning as disjunct occurs primarily through ellipsis.

\section{REFERENCES}

[1] Foster B. (1995) The Changing English Language. Oxford: Clarendon Press.

[2] Yartseva N. (1969) Limits for Extension of Structures via the Scope of Information. Moscow. (in Russian)

[3] Dyundik B. (2013) http://knu.znate.ru/docs/index-441992.ht $\mathrm{ml}$.

[4] Martinet A. (1960) Fundamentals of General Linguistics // Recent Issues in Linguistics. Military Literature Publishing House, pp. 365-565. Moscow. (in Russian)

[5] Vardul I. (2006) Fundamentals of Descriptive Linguistics. Moscow: URSS. (in Russian)

[6] Larkina A. (2012) http://www/sworld.com.ua/index.php/ru/modern-linguisticsand- intercultural communication.

[7] Matthews P.H (1997) Oxford Concise Dictionary of Linguistics. Oxford University Press.

[8] Biber D. et al. (2000) Grammar of Spoken and Written English. London: Longman.

[9] Kreidler Ch. W. (2002) Introducing English Semantics. Routledge: London and New York, 2002.

[10] Radford A. (2009) Analyzing English Sentences. A Minimalist Approach. Cambridge University Press.

[11] Payne Th. E. (2011) Understanding English Grammar. Cambridge University Press.

[12] Mathesius J. (1967) The Main Function of Word Order in the Czech Language // The Prague Linguistic School, pp. 246265. Moscow. (in Russian)

[13] Sweet H. (1931) A New English Grammar: Logical and Historical. Oxford.

[14] Quirk R and S. Greenbaum (1978) A University Grammar of English. London: Longman.

[15] Leech G., G. Svartvik (1983) A Communicative Grammar of English. Moscow: Prosveshcheniye.

[16] Palmer F.R. (1986) Mood and Modality. Cambridge University Press.

[17] Huang Shuan-Fan. (1975) A Study of Adverbs. The Hague: Mouton \& Co. B. V.

[18] Hyland K. (1998) Hedging in Scientific Research Articles. Amsterdam/ Philadelphia: John Benjamins Publishing Company.

[19] Kobrina N. et al (2007) Theoretical Grammar of Modern English. Moscow: Visshaya Scola.

[20] Talmy L. (1988) Force Dynamics in Language and Cognition // Cognitive Science, No12, pp.49-100. 
[21] Gleitman L \& M. Liberman (1995) The Cognitive Science of Language // Invitation to Cognitive Science, MIT Press, pp. xix-xxxi.

[22] https://www.google.am/webhp?sourceid=chrome-instant\&io $\mathrm{n}=1 \&$ espv $=2 \&$ ie $=U T F-8 \# \mathrm{q}=$ www.irishmirror.ie $+\% \mathrm{E} 2 \% 80 \%$ $\mathrm{BA}+\mathrm{News}+\% \mathrm{E} 2 \% 80 \% \mathrm{BA}+$ World + News $+\% \mathrm{E} 2 \% 80 \% \mathrm{BA}+$ Aliens

[23] Mkhitaryan Y. and Z. Kostanian (2006) English Syntax (exercises). Yerevan: Zangak. 